\title{
Alismataceae no estado do Ceará, Brasil
}

\author{
Alismataceae in Ceará State, Brazil
}

\author{
Lígia Queiroz Matiass ${ }^{1,2}$ \& Danilo José Lima de Sousa ${ }^{1}$
}

\begin{abstract}
Resumo
Apresenta-se aqui o levantamento florístico da família Alismataceae latu sensu para o estado do Ceará, Nordeste do Brasil, região caracterizada por clima semiárido, onde são abundantes os ecossistemas aquáticos temporários. Quatro gêneros e 13 espécies foram identificados. As espécies indicadas para o estado são: Sagittaria guayanensis, S. planitiana, Echinodorus tenellus, E. glandulosus, E. pubescens, E. subalatus, E. palaefolius, E. floribundus, E. lanceolatus, Limnocharis laforestii, L. flava, Hydrocleys martii, H. nymphoides. São apresentadas descrições, comentários taxonômicos, ilustrações, chaves de identificação e dados da distribuição geográfica das espécies.
\end{abstract}

Palavras-chave: áreas inundadas, macrófitas aquáticas, regiões semiáridas.

\begin{abstract}
A floristc survey of Alismataceae latu sensu from Ceará state, Northeastern Brazil, is presented. This region is characterized by a semiarid climate where intermittent aquatic ecosystems are common. Four genera and 13 species were identified. The species are: Sagittaria guayanensis, S. planitiana, Echinodorus tenellus, E. glandulosus, E. pubescens, E. subalatus, E. palaefolius, E. floribundus, E. lanceolatus, Limnocharis laforestii, L. flava, Hydrocleys martii, H. nymphoides. Descriptions, taxonomic observations, illustrations, keys for identification of the species and data on geographic distribution are presented.
\end{abstract}

Key words: aquatic macrophytes, semi-arid regions, wetlands.

\section{Introdução}

Os representantes de Alismataceae são caracterizados pelo hábito herbáceo e aquático, cujas flores radiais e trímeras possuem estames com anteras extrorsas e gineceu apocárpico (Haynes et al. 1998). Os diferentes padrões de ornamentação da superfície de sementes, em Echinodorus, apresentam importância na sistemática entre as categorias infragenéricas (Matias \& Soares 2009). As características morfológicas incluem ainda a presença de escamas diminutas situadas entre as bainhas foliares, endosperma ausente e pelos epidérmicos radiculares reduzidos (Dahlgren \& Rasmussen 1983).

O posicionamento basal em relação às demais monocotiledôneas foi indicado por Takhtajan (1980), Dahlgren et al. (1985), Cronquist (1981, 1988), Thorne (1992, 2000) e APG III (2009). No entanto, as relações filogenéticas entre Alismataceae e as demais monocotiledôneas basais ainda permanecem incertas, apesar de estudos analisarem diferentes tipos de evidências taxonômicas (Les \& Haynes 1995; Dahlgren \& Rasmussen 1983). Em análises que consideraram as delimitações stricto sensu de Alismataceae Vent. e Limnocharitaceae Takht., os resultados demonstram a existência de forte parentesco entre estas famílias (Les \& Haynes 1995; Li \& Zhou 2009). Isto fortalece os sistemas de classificação propostos por Pichon (1946), Dahlgren et al. (1985), Thorne (1992) e APG III (2009), que incluíram os gêneros Limnocharis Humb. \& Bonpl. e Hydrocleys Rich. em Alismataceae.

Considerando esta ampla circunscrição, a família foi considerada monofilética por Dahlgren $e t$ al. (1985) e Les \& Haynes (1995) com base em evidências morfológicas e moleculares. Desta forma, a família Alismataceae encontra-se representada por 15 gêneros e cerca de 80 espécies (Stevens 2001). Na região neotropical ocorrem os gêneros Echinodorus Engelm., Sagittaria L., Hydrocleis Rich. e Limnocharis Humb. \& Bonpl. (Haynes \& Holm-Nielsen 1992, 1994; Cook 1996; Haynes et al. 1998).

\footnotetext{
${ }^{1}$ Universidade Federal do Ceará, Centro de Ciências, Depto. Biologia, Lab. Taxonomia de Angiospermas, bl. 906, Campus do Pici, 60451-760, Fortaleza, CE, Brasil.
} 
Os levantamentos florísticos da família Alismataceae para a América do Sul registraram a ocorrência comum dos quatro gêneros acima citados nos ambientes aquáticos (perenes ou temporários) em regiões semiáridas brasileiras, com ocorrência de endemismos (Haynes \& HolmNielsen 1992, 1994; Matias \& Irgang 2006; Matias 2007). O presente trabalho objetivou a identificação das espécies de Alismataceae e a localização das populações no estado do Ceará, fornecendo informação sobre a flora de ecossistemas aquáticos que servirá de subsídios para a conservação e o manejo das áreas alagadas. Sendo assim, este estudo contempla uma das propostas realizadas pela Conferência dos Países signatários da Convenção Mundial da Biodiversidade que estabeleceu programas que visam estudos sobre a diversidade de áreas alagadas continentais (COP-04 1998).

\section{Material e Métodos}

Foram analisados espécimes de Alismataceae provenientes de coletas, assim como de material depositado em acervos botânicos (BM, EAC, HCDAL, HST, IPA, JPB, MOSS, PEUFR, RB, S, P, TEPB, UFP, UFRN, URM, as siglas seguem Thiers 2010). Apenas um grupo selecionado de amostras foi citado, mas a listagem completa de exsicatas analisadas consta ao final do trabalho. A classificação de Alismataceae está de acordo com Lehtonen (2008). A identificação foi realizada através de consulta a bibliografia específica (Matias \& Irgang 2006; Matias 2007; Lehtonen 2008), além de consultas a sites especializados onde estão disponibilizadas imagens de materiais tipos. Os espécimes coletados foram herborizados seguindo a metodologia de Haynes (1984) e Ceska (1986) e depositados no herbário EAC. As formas de crescimento foram analisadas segundo Irgang \& Gastal (1996) e a terminologia morfológica segue Harris \& Harris (1997) e Cannon (1949). As abreviações dos nomes dos autores estão de acordo com IPNI (2010). Para a indicação da distribuição geográfica, utilizou-se o modelo de mapa que segue um sistema de quadrículas georreferenciadas do estado do Ceará, com grades de meio grau (Fig. 1). A localização das populações foi determinada com base no município de coleta ou quando disponíveis, a partir das coordenadas geográficas referidas nas etiquetas das exsicatas, sendo indicada a(s) quadrícula(s) correspondente(s).

\section{Resultados e Discussão \\ Tratamento taxonômico}

Alismataceae Vent., Tabl. Regn. Veg. 2: 157. 1799. Plantas dióicas, aquáticas, enraizadas. Sistema subterrâneo descentralizado, rizomatoso, caules estoloníferos, ocasionamente, presentes. Folhas alternas, espiraladas, com entrenós muito curtos, simples, inteiras; predominantemente acródomas; lâminas foliares lineares quando submersas, elípticas a ovadas quando emersas ou flutuantes; estípulas ausentes. Inflorescências racemosas ou cimosas, terminais sobre um escapo; brácteas verdes. Flores diclinas ou monoclinas, radiais; sépalas 3, livres, imbricadas; pétalas 3, livres, imbricadas, elípticas, ovadas ou obovadas, geralmente brancas. Estames 6 a numerosos; filetes livres; anteras dorsifixas, versáteis, raro basifixa. Carpelos 3 a numerosos, livres; ovário apocárpico, súpero; estilete persistente; estigma 1, diminuto; uniovulado; placentação basal. Aquênios ovóides, obovóides ou semicirculares, abaulados ou achatados dorsiventralmente, superfície lisa ou costelada, glândulas geralmente presentes. Semente com embrião recurvado, endosperma ausente.

\section{Chave para identificação dos gêneros de Alismataceae do Ceará}

1. Flores diclinas

1. Sagittaria

1'. Flores monoclinas.

2. Carpelos uniovulados

2. Echinodorus

2'. Carpelos pluriovulados.

3. Pecíolos trígonos, não septados. Frutos lateralmente compressos, apresentando sulco dorsal

3'. Pecíolos cilíndricos, septados. Frutos abaulados, não apresentando sulco dorsal 


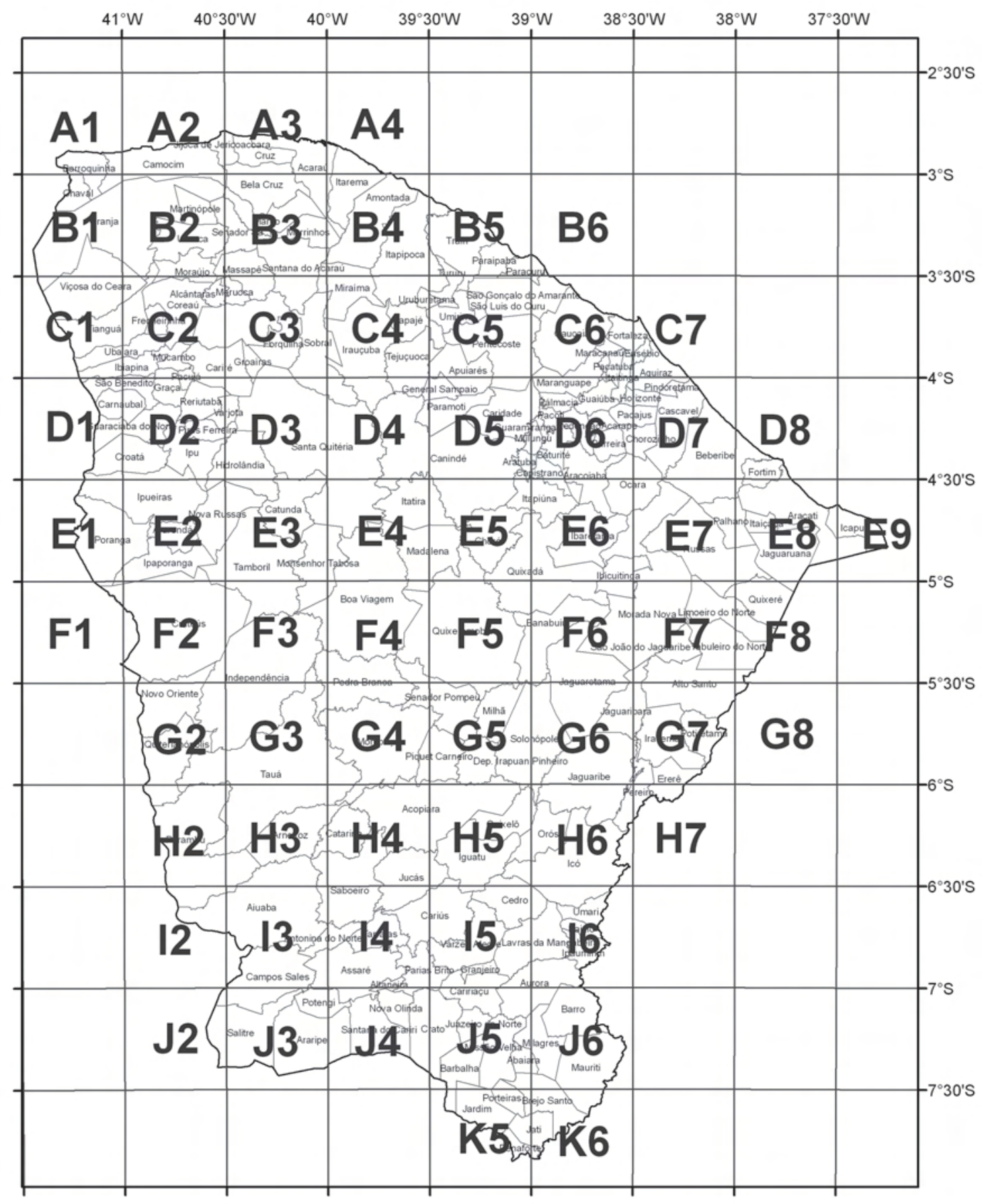

Figura 1 - Mapa do estado do Ceará (CE), Brasil, evidenciando o sistema de quadrículas georreferenciadas (A1-K6). Figure 1 - Map of Ceará state (CE), Brazil, showing the system of georeferenced squares grid (A1-K6). 
1. Sagittaria L. Sp. Pl. 2: 993. 1753.

Ervas enraizadas no substrato com folhas flutuantes ou partes vegetativas emergentes. Folhas elípticas, ovadas ou reniformes; acródomas ou campilódromas; ápice agudo a arredondado; base cordada a arredondada; ductos secretores translúcidos ausentes; pecíolo trígono ou cilíndrico, não septado, glabro a pubescente. Inflorescências racemosas, flutuantes ou eretas; pseudoviviparidade ausente; escapo ereto ou flutuante, glabro a pubescente, cilíndricos, inflados na extremidade distal ou não, não alados; verticilos 3-9, verticilos inferiores com flores pistiladas, verticilos superiores com flores estaminadas. Brácteas lanceoladas, membranáceas, glabras; ápice agudo; base livre. Flores diclinas com pedicelos eretos a levemente recurvados; sépalas ovadas, cônicas, membranáceas, lisas, glabras a pubescentes, persistentes adpressas; pétalas alvas. Flores estaminadas com verticilo de carpelos estéreis presentes ou não. Estames numerosos, anteras dorsifixas. Flores pistiladas com verticilo de estaminódios presentes ou não. Carpelos numerosos, uniovulados. Aquênios obovados, abaulados, superfície lisa ou ornamentada. Sementes ca. $1 \mathrm{~mm}$ compr.

\section{Chave para identificação das espécies de Sagittaria ocorrentes no estado do Ceará}

1. Plantas com folhas membranáceas, delicadas; escapo glabro, não inflado na extremidade distal, flexível; aquênios com superfície tuberculada 1.1. S. guayanensis

1'. Plantas com folhas cartáceas; escapo pubescente, inflado na extremidade distal, ereto; aquênios com superfície lisa 1.2. S. Planitiana

1.1 Sagittaria guayanensis Kunth, Nov. Gen. Sp. 1:250. 1816.

Fig. 2a-d

Ervas, $18-45 \mathrm{~cm}$ alt., enraizadas no substrato com folhas flutuantes, glabrescentes. Rizomas cilíndricos, $1-1,5 \mathrm{~cm}$ diâm. Folhas ovadas a elípticas, 5,5-8,5 cm comp., 3.9-5,5 cm larg.; ápice agudo a arredondado; base cordada a arredondada; membranáceas, delicadas; campilódromas, 11-12 nervada. Pecíolo 15-57 cm compr., 0,2-0,5 cm larg., pubescente; bainha ca. $4,5 \mathrm{~cm}$ compr. Inflorescência racemosa, flutuante; escapo trígono, glabro, não inflado na extremidade distal, flexível, $10-17 \mathrm{~cm}$ compr., 0,5-0,7 cm diâm.; eixo 5-8 cm compr., glabro, não inflado, verticilos 5-7. Brácteas lanceoladas, 510 mm compr., 3-9 mm larg., membranáceas, glabras, 12-14 nervada. Flores estaminadas com pedicelos eretos a levemente recurvados, 6-9 $\mathrm{mm}$ compr.; sépalas ovadas, ca. $5 \mathrm{~mm}$ compr., ca. $6 \mathrm{~mm}$ larg., 2029 nervada, persistentes, adpressas; pétalas ca. 6 mm compr., ca. $5 \mathrm{~mm}$ larg., alvas com máculas amarelas na base. Estames 12, verticilo de carpelos estéreis presente. Flores pistiladas com pedicelos eretos, 15$16 \mathrm{~mm}$ compr.; sépalas $10-11 \mathrm{~mm}$ compr., $10-12 \mathrm{~mm}$ larg., 28-35 nervada, persistentes, adpressas; pétalas 8-10 mm compr., 5-8 mm larg., verticilo de estames estéreis presentes. Aquênios obovados, não carenados, ca. $3 \mathrm{~mm}$ compr., ca. $2 \mathrm{~mm}$ larg., superfície tuberculada, alas ausentes, carenados; estruturas secretoras ausentes. Sementes ca. $1 \mathrm{~mm}$ compr.

Material examinado: Crateús, 25.VI.2004, fl. e fr., $L . Q$. Matias 455 (EAC).
Espécie pantropical (Haynes \& Holm-Nielsen 1994). Nos continentes asiático e africano ocorre $S$. guayanensis spp. lapulla (D. Don) Bogin, enquanto S. guayanensis spp. guayanensis possui distribuição restrita ao continente americano (Matias 2010). Porém, poucas populações foram encontradas no Ceará, ocupando margens de lagoas temporárias ou açudes da região semiárida no noroeste do estado (Fig. 1 B2, C3). A identificação dos táxons infraespecíficos ocorre pelas variações morfológicas dos frutos, sendo estes pequenos $(<2,5 \mathrm{~mm})$ e abaulados em $S$. guayanensis spp. guayanensis.

1.2 Sagittaria planitiana G. Agostini, Phytologia 20:1. 1970.

Fig. 2e-i

Ervas, $25-35 \mathrm{~cm}$ de alt., enraizadas no substrato com partes vegetativas emersas, pubescentes. Rizomas cilíndricos, $2-3 \mathrm{~cm}$ diâm. Folhas ovadas a reniformes, 6-9 cm compr., 9-12 cm larg.; ápice arredondado; base cordada a reniforme; cartáceas, acródoma, 12-14 nervada. Pecíolo 25-29 cm compr., $0,3-0,5 \mathrm{~cm}$ larg., pubescente na extremidade distal; bainha 4,5-8 cm compr. Inflorescências racemosas, eretas; escapo cilíndrico, pubescente e inflado na extremidade distal, rígido, $26-30 \mathrm{~cm}$ compr., $0,5-0,7 \mathrm{~cm}$ diâm.; eixo 4-9 cm compr., pubescente e inflado no verticilo inferior, 3-9 verticilos. Brácteas elípticas, 10 15 mm compr., $10-18$ mm larg., glabras, 36-42 nervada. Flores estaminadas com pedicelos recurvados, 6-9 $\mathrm{mm}$ compr.; sépalas 16-18 mm compr., 12-16 mm de larg, 30-32 nervada, persistentes, adpressas; pétalas 10$15 \mathrm{~mm}$ compr., 0,5-0,8 mm larg., alvas. Estames 10-16, 


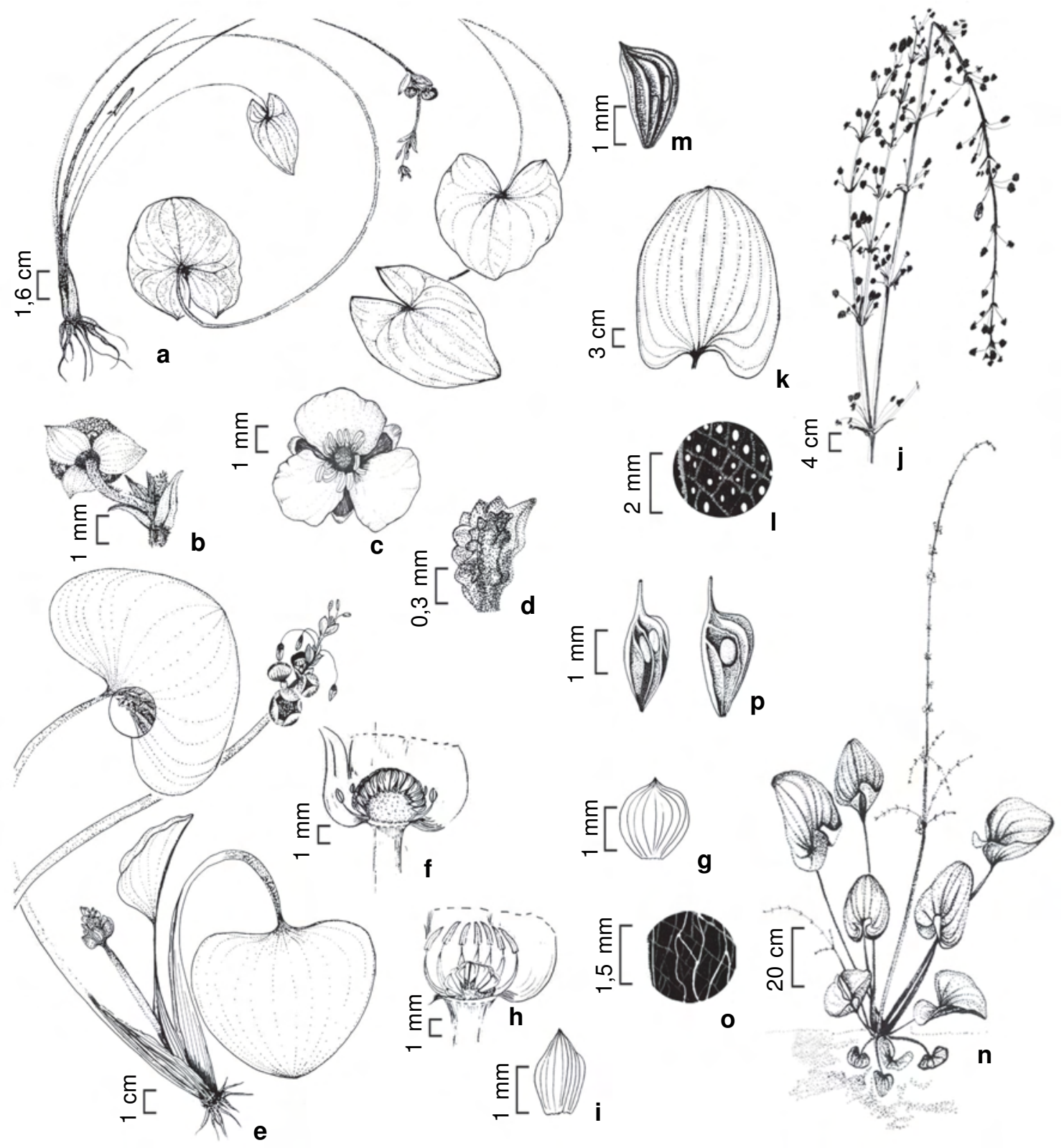

Figura 2 - a-d. Sagittaria guayanensis (Matias 455) - a. hábito; b. flor estaminada; c. flor pistilada; d. aquênio. e-i. S. planitiana (Fernandes s.n. EAC 22996) - e. hábito; f. flor pistilada; g. bráctea da flor pistilada; h. flor estaminada; i. bráctea da flor estaminada. j-m. E. floribundus (Lützelburg 25911) - j. inflorescência; k. folha; 1. detalhe da folha evidenciando ductos secretores pontuais; m. aquênio. n-p. E. glandulosus (Matias 352) - n. hábito; o. detalhe da folha evidenciando ductos secretores reticulares; p. aquênios.

Figure 2 - a-d. Sagittaria guayanensis (Matias 455) - a. habit; b. staminate flower; c. pistillate flower; d. achene. e-i. S. planitiana (Fernandes s.n. EAC 22996) - e. habit; f. pistillate flower; g. pistillate bracts; h. staminate flower; i. staminate flower bracts. $\mathrm{j}-\mathrm{m}$. E. floribundus (Lützelburg 25911) - j. inflorescence; k. leaf; l. details of leaf showing a network of secretor ducts; $\mathrm{m}$. achene. n-p. E. glandulosus (Matias 352) - n. habit; o. details of leaf showing a network of secretor ducts; p. aquene. 
verticilo de carpelos estéreis presente. Flores pistiladas com pedicelos eretos, 10-18 mm compr.; sépalas 11,5 mm compr., 1,5-1,7 mm larg., 23-28 nervada, persistentes, adpressas; pétalas $10-18 \mathrm{~mm}$ compr., 10-16 mm larg., alvas, verticilo de estames estéreis presente. Aquênios obovados, carenados, 3-3,5 mm compr., 1-1,2 mm larg., superfície lisa com duas nervuras evidentes acompanhando o formato do fruto, alas 2, carenados; ductos secretores adjuntos às alas. Sementes ca. $1.5 \mathrm{~mm}$ compr.

Material examinado: Sobral, 15.VI.1995, A. Fernandes s.n. (EAC 22996).Uruoca, 5.V.2006, fl.,A.S.F. Castro 1771 (EAC).

A espécie é restrita à região tropical da América do Sul (Haynes \& Holm-Nielsen 1994). No Brasil existem registros para as regiões sazonais sob domínio do cerrado, da caatinga e para a região Amazônica (Matias 2010). No Ceará, as populações foram registradas para a região noroeste (Fig. 1 B2, C3), ocupando lagoas temporárias ou açudes da região semiárida do estado. A espécie possui forma de crescimento enraizada no substrato com partes vegetativas emergentes, diferenciando-se de S. guayanensis que possui folhas flutuantes.
2. Echinodorus Rich. ex Engelm. in A. Gray, Man. Bot. 460.1848.

Ervas enraizadas no substrato com partes vegetativas emersas, monóicas. Folhas elípticas, ovadas ou sagitadas; acródomas ou campilódromas; ápice agudo, arredondado ou levemente retuso; base sagitada a cordada; ductos secretores translúcidos reticulares, punctiformes ou lineares; pecíolo cilíndrido a trígono, não septado, glabro a pubescente. Inflorescências racemosas emersas; pseudoviviparidade ocasionalmente presente; escapo ereto, glabro a pubescente, semicircular a trígono, não inflado, alado ou não; verticilos 2-33. Brácteas ovadas a lanceoladas, coriáceas ou membranáceas, glabras a pubescentes; ápice agudo; base livre. Flores monoclinas com pedicelos eretos a levemente recurvados; sépalas ovadas, cônicas, coriáceas, costeladas, glabras a pubescentes, persistentes, reflexas; pétalas alvas. Estames 6-24, anteras dorsifixas, raro basifixas. Carpelos numerosos, uniovulados. Aquênios obovados, abaulados, superfície ornamentada. Sementes obovadas, ca. $1 \mathrm{~mm}$.

\section{Chave para identificação das espécies de Echinodorus ocorrentes no estado do Ceará}

1. Plantas diminutas (7-10 cm alt.), sistema subterrâneo centralizado, flores com 6-9 estames 2.7. E. tenellus

1'. Plantas copiosas (20-190 cm alt.), sistema subterrâneo descentralizado, flores com 12-26 estames.

2. Flores com doze estames.

3. Lâmina foliar amplo-ovada, base sagitada a cordada, pecíolo glabro .......2.2. E. glandulosus

3'. Lâmina foliar ovada a elíptico-lanceolada, base atenuada, cuneada ou truncada, pecíolo pubescente a glabrescente.

4. Plantas pubescentes

2.5. E. pubescens

4' Plantas glabrescentes a glabras.

5. Escapo semicircular, alado a subalado, 2 alas, 0,5-2 $\mathrm{mm}$ larg., eixo não alado a subalado, alas 0,5-1 mm larg. .................................................. 2.6. E. subalatus

5. Escapo pentagonal, amplo alado, 3-5 alas, 3-8 mm larg., eixo alado, alas 1,5-5,3 mm larg. 2.4. E. palaefolius

2'. Flores com mais de doze estames.

6. Lâmina foliar ovada com base cordada, superfície dorsal glabrescente a pubescente, ductos secretores translúcidos, marcas pontuais, nervação campilódroma ........... 2.1. E. floribundus

6'. Lâmina foliar elíptico-lanceolada com base cuneada a atenuada, superfície dorsal glabra, ductos secretores ausentes, nervação acródoma 2.3. E. lanceolatus

2.1 Echinodorus floribundus (Seub.) Seub., Vidensk. Meddel. Dansk Naturhist. Foren. Kjøbenhavn 6-9: 345. 1872.

Fig. $2 \mathrm{j}-\mathrm{m}$

Ervas ca. 2,4 m alt., pubescentes a glabrescentes, tricomas pluricelulares, estrelados. Rizomas cilíndricos, $2-5 \mathrm{~cm}$ diâm. Folhas ovadas, $19-50 \mathrm{~cm}$ compr., $12-48 \mathrm{~cm}$ larg.; ápice acuminado, arredondado a levemente retuso; base cordada a sagitada; campilódromas, 12 17 nervada, lobos $1-6 \mathrm{~cm}$ compr., 3,5-10 cm larg., 2-3 nervado; ductos secretores translúcidos pontuais. Pecíolo cilíndrido, 12-30 cm compr., 0,5-1 cm larg.; bainha 8-23 cm compr. Inflorescências paniculiformes, pseudoviviparidade presente; escapo $18-102 \mathrm{~cm}$ compr., trígono, não alado; eixo 30-63 cm compr., 12- 
14 verticilos, não alado. Brácteas ovadas a lanceoladas, 8-16 mm compr., 0,5-7 mm larg., glabras, coriáceas, 1218 nervada. Pedicelo floral 10-22 mm compr., glabro. Sépalas 4-6,5 mm compr., 4,5-5 mmlarg., 10-12 nervada, glabras; pétalas 10-12 mm compr., 8-12 mm larg. Estames 18-26, anteras dorsifixas. Carpelos numerosos, superiores a 20. Aquênios oblanceolados, 3-3,2 mm compr., 1-1,5 mm larg., 5-6 costelados, glabros, glândulas 1-2, lenticulares. Sementes obovaladas, ca. $1,6 \mathrm{~mm}$ compr.

Material examinado: Granjeiro, 11.XII.1933, P. Lützelburg 25911 (EAC). Crato, VIII.1938, G. Gardner 1860 (BM, P).

A espécie ocorre na América do Sul e Central (Haynes \& Holm-Nielsen 1994). No Brasil ocorre na Amazônia e nas matas úmidas do Sudeste e do Sul (Matias 2010). Existem registros antigos desta espécie para o sul do estado do Ceará (Fig. 1 - I5, J5), entretanto estas populações não foram localizadas em expedições recentes. O hábito desta espécie é semelhante ao de E. glandulosus, porém as folhas cordiformes de E. floribundus possuem pontuações translúcidas, diferente do retículo translúcido observado nas folhas de E. glandulosus. Além disto, E. floribundus possui flores com número muito elevado de estames em relação aos encontrados em E. glandulosus (apenas doze).

2.2 Echinodorus glandulosus Rataj, Folia Geobot. Phytotax. 4: 336. 1969.

Fig. 2n-p

Ervas $80-185 \mathrm{~cm}$ alt., glabrescentes a glabras, tricomas simples. Rizomas claviformes, $1,5-5 \mathrm{~cm}$ compr., 1-3 cm larg. Folhas amplo-ovadas, $10-22 \mathrm{~cm}$ compr., 8-25 cm larg.; ápice arredondado a levemente retuso; base cordada a sagitada; campilódromas, 1114 nervada; lobos 1,9-2,8 cm compr., 2-4,5 cm larg., 2-4 nervado; ductos secretores translúcidos reticulares. Pecíolo cilíndrico, 20-75 cm compr., 0,8-1 cm larg.; bainha 4-30 cm compr. Inflorescências paniculiformes, pseudoviviparidade ausente; escapo 59-109 cm compr., cilíndrico, não alado; eixo 21-95 cm compr., 11-33 verticilos, não alado. Brácteas ovadas, 5,5-7 mm compr., 4-4,5 mm larg., glabrescentes, coriáceas, 8-14 nervada. Pedicelo floral 7-10 mm compr., glabro. Sépalas 4-5 mm compr., 3-5 mm larg., 12-16 nervada, glabras a glabrescentes, pétalas 15-16 mm compr., 7-14 mm larg. Estames 12, anteras dorsifixas. Carpelos numerosos, superiores a 20. Aquênios obovados, 2,2-2,5 mm compr., 1-1,5 mm larg., 3-4 costelados, glabros, glândula 1, raro 2, discoide. Sementes obovadas, ca. 1,2 mm compr.

Material examinado: Aiuaba, 9.V.200, fl. e fr., L.Q. Matias 352 (EAC). Antonina do Norte, 18.V.2003, fl. e fr., L.Q. Matias 421 (EAC). Arneiroz, 8.V.2002, fl., L.Q. Matias 349 (EAC). Caucaia, 16.VII.2006, fl., A.S.F. Castro
1824 (EAC). Crato, 13.VII.1948, A.P. Duarte 1408 (RB). Independência, 25.VI.2003, fl., L.Q. Matias 462 (EAC). Itapipoca, 17.VIII.2003, fl. e fr., L.Q. Matias 483 (EAC). Parambu, 11.IV.2003, fl. e fr., L.Q. Matias 375 (EAC).

A espécie é endêmica do nordeste do Brasil (Haynes \& Holm-Nielsen 1994), com registros para os estados do Ceará, Bahia, Paraíba e Pernambuco (Matias 2010). No Ceará, as populações são muito comuns em lagoas temporárias do sul do estado (Fig. 1-B4, C6, F3, I3, I4, H2, H3). O porte robusto e as folhas cordiformes tornam esta espécie semelhante a E. floribundus, porém E. glandulosus apresenta as folhas com marcas translúcidas em forma de retículo e as suas flores têm apenas doze estames.

2.3 Echinodorus lanceolatus Rataj, Bull. Jard. Bor. Belg. 38: 406. 1968.

Fig. 3a-b

Ervas 23-70 m alt., glabras. Rizomas fusiformes, $3-4,5 \mathrm{~cm}$ compr., 2,5-3 cm larg. Folhas lanceoladas ou elípticas, 4,5-20 cm compr., 0,5-4,5 cm larg.; ápice acuminado ou agudo; base atenuada ou cuneada; acródroma, 5-7 nervada; ductos secretores não translúcidos. Pecíolo trígono, 17-99,5 cm compr., 1,11,3 cm larg.; bainha 5-25 cm compr. Inflorescências paniculiformes, pseudoviviparidade presente; escapo 50-127,5 cm, trígono, alado, alas 3, 0,5-1,5 mm larg.; eixo 27-29 cm compr., 5-9 verticilos, não alado. Brácteas ovadas a lanceoladas, 10-25 mm compr., 3-6 mm larg., glabras, coriáceas, 13-17 nervada. Pedicelo floral 3-3,5 mm compr., glabro. Sépalas 10-11 mm compr., 3-4 mm larg., 15-19 nervadas, glabrescentes, tricomas sobre as nervuras centrais; pétalas $10-12 \mathrm{~mm}$ compr., 8-12 mm larg. Estames 19-24, anteras dorsifixas. Carpelos numerosos, superior a 20. Aquênios obovados, 2-2,4 mm compr., 1-1,3 mm larg., 4 costelados, tricomas raramente presentes sobre as costelas, glândulas 24, discoides. Sementes oblongas, ca. 1,33 mm compr. Material examinado: Granja, 23.V.2002, fl., L.Q. Matias 361 (EAC). Iguatu, 6.IX.2009, fl. e fr., L.Q. Matias s.n. (EAC 45463). Jacobina, 11.VI.2008, M. Andrade Neto s.n. (EAC).

Os registros da espécie são restritos ao nordeste brasileiro (Haynes \& Holm-Nielsen 1994; Matias 2010). No estado do Ceará, as populações podem ser observadas em lagoas temporárias na região semiárida do estado (Fig.1 -B2, H5). As folhas longo pecioladas e lanceoladas são características, associado ao pecíolo espesso e aerenquimatoso.

2.4 Echinodorus palaefolius (Nees \& Mart.) J.F. Macbr., Publ. Field Mus. Nat. Hist., Bot. Ser. 11(1): 4. 1931.

Fig. 3c-e

Ervas $31-178 \mathrm{~cm}$ alt., glabrescentes ou glabras, tricomas simples. Rizomas fusiformes, 2,5-4 cm compr., $1,5-3 \mathrm{~cm}$ larg. Folhas ovadas a elípticas, 9-36 cm compr., 
4-21 cm larg.; ápice agudo, arredondado a levemente retuso; base truncada, arredondada, cordada a sagitada; acródromas ou campilódromas, 5-11 nervada; lobos 0,5-1 cm compr., 2,5-3 cm larg., 1 nervado, ductos secretores inconspícuos, lineares. Pecíolo semicircular ou poligonal, 13-77 cm compr., 0,51,3 cm larg.; bainha 5-28 cm compr. Inflorescências paniculiformes, pseudoviviparidade ausente; escapo 13-89 cm compr., pentagonal, alado, alas 3-5, 3-8 mm larg.; eixo 19-80 cm compr., 5-18 verticilos, alado, alas 3, 1,5-5,3 mm larg. Brácteas ovadas, 1,16-28 mm compr., 0,5-7 mm larg., glabrescentes, coriáceas, 10-22 nervada. Pedicelo floral 2-90 mm compr., glabro a glabrescente. Sépalas 4-7 mm compr., 3-5 mm larg., 9-17 nervada, glabrescentes, tricomas sobre as nervuras centrais; pétalas, 9-22 mm compr., 6-15 mm larg.. Estames 12, anteras dorsifixas. Carpelos numerosos, superior a 20. Aquênios obovados, 0,4-1,8 mm compr., 0,2-2,88 mm. larg., 4-9 costelados, tricomas presentes sobre as costelas, glândulas 1-2, lenticulares ou discoides. Sementes obovadas, ca. 1,3 mm compr.

Material examinado: Aiuaba, 26.VI.2003, fl., L.Q. Matias 464 (EAC). Arneiroz, 8.V.2002, fl. e fr., L.Q. Matias 348 (EAC). Crateús, 24.VI.2003, fl., L.Q. Matias 442 (EAC). Crato, 16.V.2003, fl., L.Q. Matias 418 (EAC). Jati, 4.V.2003, fl., L.Q. Matias 338 (EAC). Tauá, 9.VI.2008, M. Andrade Neto et al. s.n. (EAC 43683).

A espécie é endêmica do Nordeste do Brasil (Haynes \& Holm-Nielsen 1994), com registros para os estados de Alagoas, Bahia, Ceará, Paraíba e Pernambuco (Matias 2007, 2010). As populações estão restritas a lagoas e rios intermitentes da região semiárida do estado (Fig. 1-F2, G3, H3, I3, J5, K6). As folhas de $E$. paleofolius não possuem marcas translúcidas ou quando presentes são de difícil visualização. Além disto, a espécie pode ser facilmente reconhecida pelas alas amplas situadas no escapo pentagonal e no eixo trígono da inflorescência.

2.5 Echinodorus pubescens (Mart.) Seub. ex Warm., Vidensk. Meddel. Dansk Naturhist. Foren. Kjøbenhavn 1873: 113.1873. Fig. 3f-h

Ervas $32-168 \mathrm{~cm}$ alt., pubescentes, tricomas simples. Rizomas fusiformes, 2,5-5 cm compr., 1,5-2 $\mathrm{cm}$ larg. Folhas lanceoladas, elípticas ou ovadas, 932 cm compr., 4-22 cm larg.; ápice agudo, obtuso ou arredondado; base cordada a sagitada; acródromas ou campilódromas, 5-14 nervada, lobos 1-2 cm compr., 2-3 cm larg., 1 nervado, ductos secretores não translúcidos. Pecíolo trígono, 4,5-60 cm compr., 0,1-0,7 cm larg.; bainha 6-29 cm compr. Inflorescências paniculiformes, pseudoviviparidade ausente; escapo 18-87 cm compr., trígono, não alado; eixo 9,5-86 cm compr., 6-18 verticilos, não alado. Brácteas ovadas, 9-20 mm compr., 3-10 mm larg., pubescentes, coriáceas, 9-15 nervada. Pedicelo floral 8-18 mm compr., pubescente. Sépalas 4-6 mm compr., 3-6 mm larg., 9-14 nervada, pubescentes; pétalas 7$14 \mathrm{~mm}$ compr., 6-12 mm larg. Estames 12, anteras dorsifixas. Carpelos numerosos, superior a 20. Aquênios obovados, 2-3 mm compr., 1-2 mm larg., 4-7 costelados, tricomas presentes sobre as costelas, glândulas 1-2, raro 3, lenticulares ou discoides. Sementes obovadas, ca. 1,3 mm compr.

Material examinado: Aiuaba, 20.V.2003, fl., L.Q. Matias 434 (EAC). Baturité, 4.VII.1938, J. Eugenio 227 (RB). Cascavel, 9.IV.2003, fl., L.Q. Matias 373 (EAC). Crateús, 25.VI.2003, fl., L.Q. Matias 461 (EAC). Iguatu, 14.V.2010, L.R.O. Normando 112 (EAC). Ipueiras, 23.III.1910, A. Löfgren 390 (S). Quixadá, 27.VI.2008, M. Andrade Neto et al. s.n. (EAC 43682). Santa Quitéria, 16.IV.1980, fl., A. Fernandes et al. s.n. (EAC 8372). Senador Pompeu, 7.V.2002, fl., L.Q. Matias 346 (EAC).

A espécie é endêmica do Nordeste do Brasil (Haynes \& Holm-Nielsen 1994), com registros para os estados do Ceará, Bahia, Piauí e Minas Gerais (Matias 2010). Populações podem ser observadas em lagoas temporárias da região semiárida do estado, principalmente ao sul (Fig. 1-D3, D7, E6, F2, G5, H5, I3).

2.6 Echinodorus subalatus (Mart.) Griseb., Cat. Pl. Cub. 218. 1866.

Fig. 3i-1

Ervas 27-69 cm alt., glabrescentes a glabras, tricomas simples. Rizomas fusiformes, 1,5-5,5 cm compr., 1-5,5 cm larg. Folhas elípticas ou ovadas, 7$18 \mathrm{~cm}$ compr., 4-8 cm larg.; ápice agudo ou obtuso; base atenuada ou cuneada; acródromas, 5-11 nervada; ductos secretores translúcidos lineares, às vezes inconspícuos. Pecíolo trígono a sexangulado, $3-48 \mathrm{~cm}$ compr., 0,4-0,8 cm larg.; bainha 10-38 cm compr. Inflorescências racemosas simples a paniculiformes, pseudoviviparidade presente; escapo $12-60 \mathrm{~cm}$ compr., semicircular, alado a subalado, alas 2, 0,5-2 mm larg.; eixo 6-50 cm compr., trígono, 6-20 verticilos, alado a subalado, alas 0,5-1 mm larg. Brácteas ovadas, 1-40 mm compr., 2-8 mm larg., glabras a glabrescentes, coriáceas, 5-15 nervada. Pedicelos 2-28 mm compr., glabros a glabrescentes. Sépalas 4-7 mm compr., 4-5 mm larg., 9-16 nervada, glabrescentes, tricomas sobre a nervura central; pétalas 7-16 mm compr., 4.5-10 mm larg.. Estames 12, anteras dorsifixas. Carpelos numerosos, superior a 20. Aquênios obovados, 1,42,4 mm compr., 0,6-2,4 mm larg., 4-7 costelados, tricomas presentes sobre as costelas ou ausentes, glândulas 1-2, discoides. Sementes obovadas, ca. $1,2 \mathrm{~mm}$ compr. 

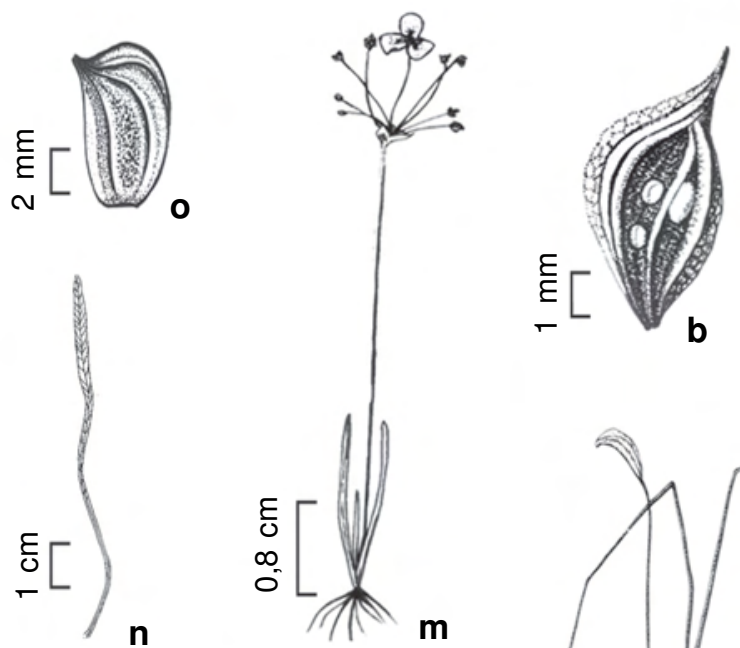

n
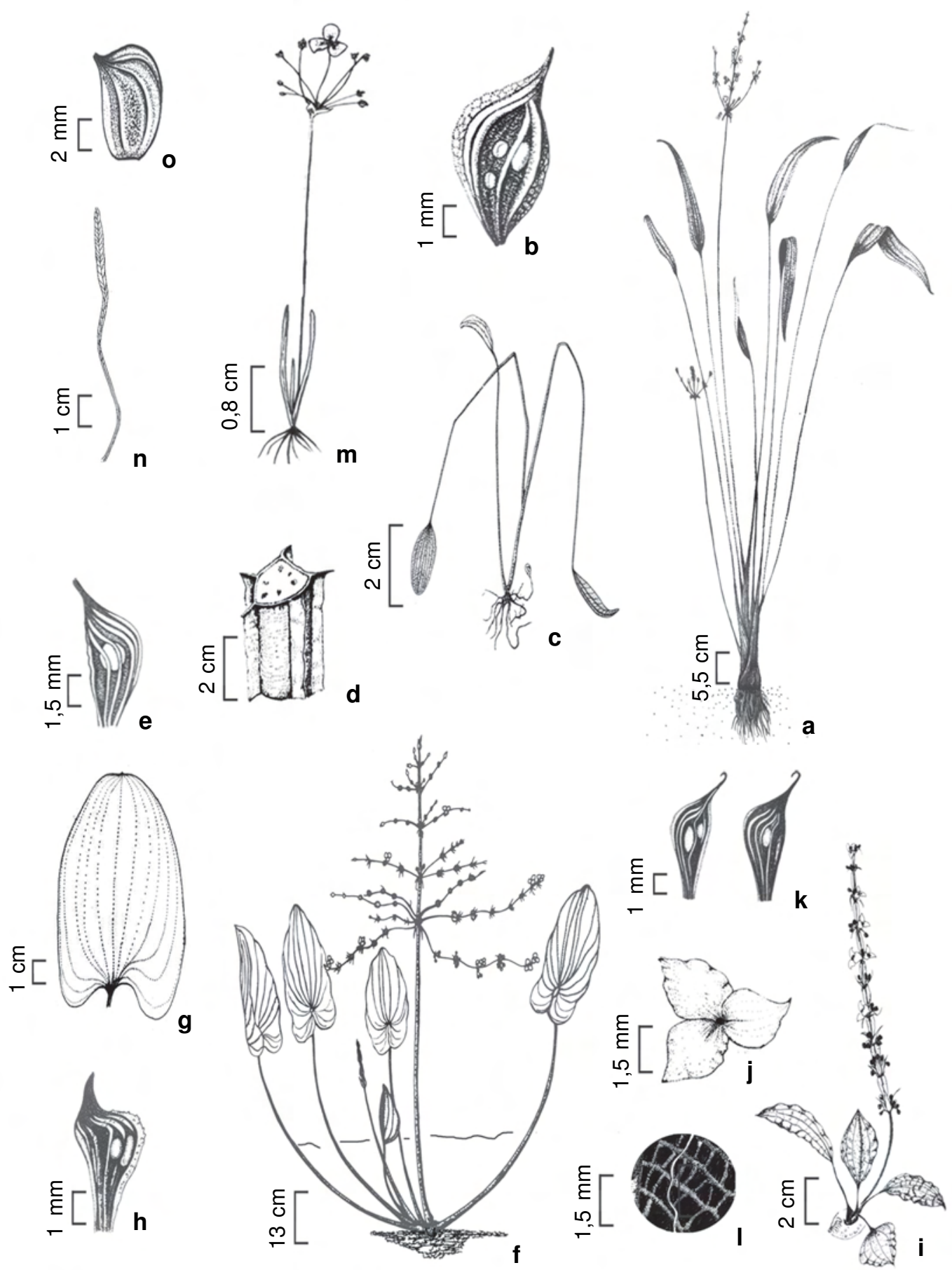

Figura 3 -a-b. Echinodorus lanceolatus (Matias 411) - a. hábito; b. aquênio. c-e. E. palaefolius (Matias 418) - c. hábito; d. escapo pentagonal; e. aquênio. f-h. E. pubescens (Matias 319) -f. hábito; g. folha ovada com base cordada; h. aquênio. i-1. E. subalatus (d Matias 343; e-g Matias 343) - i. hábito; j. flor; k. aquênios; 1 . detalhe da folha evidenciando ductos secretores lineares. m-o. E. tenellus (Matias 401) - m. hábito; n. folha; o. aquênio.

Figure 3 - a-b. Echinodorus lanceolatus (Matias 411) - a. habit; b. achene. c-e. E. palaefolius (Matias 418) - c. habit; d. pentagonal scape; e. achene. f-h. E. pubescens (Matias 319) - f. habit; g. ovate leaf with cordate base; h. achene. i-1. E. subalatus (d Matias 343; e-g Matias 343) - i. habit; j. flower; k. achenes; 1. details of leaf showing a network of secretory ducts. m-o. E. tenellus (Matias 401) - m. habit; n. leaf; o. achene. 
Material examinado: Aiuaba, 9.V.2002, fl., L.Q. Matias 355 (EAC). Antonina do Norte, 28.V.2003, fl., L.Q. Matias 422 (EAC). Barro, 11.V.2003, fl., L.Q. Matias 400 (EAC). Bela Vista, 25.V.2005, fl., L.Q. Matias 364 (EAC). Caridade, 2.VI.1991, fl., L. C. Coelho s.n. (EAC). Cascavel, 19.VII.2003, fl., L.Q. Matias 490 (EAC). Caucaia, 26.X.1999, fl., L.Q. Matias s.n. (EAC). Crateús, 24.VI.2004, fl. e fr., L.Q. Matias 444 (EAC). Forquilha, 25.V.2002, fl., L.Q. Matias 367(EAC). Fortaleza, 28.VII.1948, C. Duarte 1238 (RB). Granja, 5.XI.2007, fl., L.Q. Matias et al. 519 (EAC). Guaramiranga, 24.III.1945, H. C. Cutler 8325B (F). Icó, 12.XII.1934, P. Luetzelburg 28030 (EAC). Iguatu, 13.V.2010, L.R.O. Normando 86 (EAC). Independência, 25.VI.2003, fl. e fr., L.Q. Matias 463 (EAC). Irauçuba, 20.V.2002, fl., E. Trigueiro s.n. (EAC). Jaguaribe, 13.II.1985, A. Fernades et al. s.n. (EAC). Limoeiro do Norte, 21.VII.2008, D.J.L. Sousa 02 (EAC). Maracanaú, 1935, B.E. Dahlgren 842 (F). Paramoti, 31.III.2000, E.B. Souza 496 (EAC). Quixeramobim, 19.VI.2003, A. Fernandes et al. s.n. (EAC). São Gonçalo do Amarante, 30.I.1999, fl., E.R.A. Oliveira et al. 11 (EAC). Senador Pompeu, 6.V.2002, fl., L.Q. Matias 343 (EAC). Sobral, 25.V.1985, fl., A. Fernandes s.n. (EAC). Ubajara, 24.V.2002, fl., L.Q. Matias 363 (EAC). Uruoca, 3.V.2006, fl., A.S.F. Castro 1772 (EAC).

A espécie ocorre desde o México ao sul do continente americano (Haynes \& Holm-Nielsen 1994). No Brasil ocorrem em todos os biomas, sendo comum na região semiárida (Matias 2007, 2010). A espécie apresentou a mais ampla distribuição no estado, com registros para a região semiárida, regiões úmidas serranas e lagoas costeiras da zona litorânea (Fig. 1 B2, C2,C3, C4,C5, C6, C7, D5, F2,F3,F7,F5, G5, H5, H6, I3, I4, J6). Devido à semelhança entre os hábitos, a espécie pode ser confundida com $E$. palaefolius e $E$. pubescens. Porém, E. subalatus possui folhas glabras a glabrescentes, diferindo de E. pubescens; apresenta alas estreitas na inflorescência (parte distal do escapo e eixo da inflorescência) e escapo semicircular, enquanto E. palaefolius possui alas amplas e escapo pentagonal.

2.7 Echinodorus tenellus (Mart. ex Schult. \& Schult. f.) Buchenau, Index Crit. Butom. Alism. Juncag. 21. 1868.

Fig. 3m-o

Ervas 7-10 cm alt., glabras, estoloníferas. Rizomas oblongos, ca. $1 \mathrm{~mm}$ compr., 1-2,5 mm larg. Folhas elípticas, 1-2,5 cm compr., 1-3 mm larg.; ápice agudo; base atenuada; acródomas, 3 nervada; ductos translúcidos não visíveis. Pecíolo trígono, $0,5-1 \mathrm{~cm}$ compr.; bainha 1-12 mm compr. Inflorescências umbeliformes, pseudoviviparidade ausente; escapo 4-7 cm, cilíndrico, não alado; eixo 3-5 cm compr., não alado, 1-2 verticilos. Brácteas ovadas, 2-4 mm compr., 1-1,6 mm larg., glabras, membranáceas, 3-9 nervada. Pedicelo floral 5-25 mm compr., glabro. Sépalas 22,5 mm compr., 1-1,5 mm larg., 10-12 nervada, glabras; pétalas unguiculadas, 3-5 mm compr., 3-5 mm larg. Estames 6 a 9, anteras basifixas. Carpelos 15-20. Aquênios obovados, 1,4-2,5 mm compr., 0,5-1 mm larg., 2 costelados, eglandulares. Sementes obovadas, ca. $0,64 \mathrm{~mm}$ compr.

Material examinado: Fortaleza, D. Andrade Lima 5099 (IPA). Granja, 6.XI.2007, fl., L.Q. Matias et al. 530 (EAC). Jijoca de Jericoacoara, 9.III.1997, fl., L.Q. Matias 50 (EAC).

A espécie ocorre desde o nordeste dos Estados Unidos ao sul do Brasil (Haynes \& Holm-Nielsen 1994). No Brasil, a espécie ocorre em todos os biomas (Matias 2010) e, no Ceará, é encontrada em lagoas costeiras situadas no noroeste do estado (Fig. 1 A3, B2), associadas a solos quartzosos. Seu porte diminuto e suas inflorescências umbeliformes, cujas flores possuem poucos estames $(\leq 9)$ com anteras basifixas, tornam esta espécie muito distinta das demais que ocorrem no estado.

3. Limnocharis Humb. \& Bonpl., Pl. aequinoct. 1: 116. 1808.

Ervas enraizadas com partes vegetativas emersas, monóicas. Folhas emergentes, lanceoladas a ovadas; acródomas; ápice retuso, arredondado, às vezes mucronado; base atenuada a levemente cordada; ductos secretores translúcidos ausentes; pecíolo levemente trigono, não septados, glabros. Inflorescências cimosas emersas; pseudoviviparidade ausente; escapo ereto, glabro, cilíndrico, inflados ou não, não alados; verticilo único. Brácteas ovadas, membranáceas, glabras; ápice arredondado a mucronado; base livre. Flores monoclinas com pedicelos eretos; sépalas elípticas a ovadas, cimbiformes, coriáceas, lisas, glabras, persistentes, reflexas; pétalas amarelas. Estames numerosos, verticilo externo de estaminódios presente, ocasionalmente ausente; anteras basifixas. Carpelos numerosos, pluriovulados. Aquênios semicirculares, lateralmente compressos, apresentando sulco dorsal. Sementes numerosas.

\section{Chave para identificação das espécies de Limnocharis ocorrentes no estado do Ceará}

1. Escapo menor que o pecíolo não inflado 3.1. L. laforestii

1'. Escapo maior que o pecíolo inflado 3.2. L. flava 
3.1 Limnocharis flava (L.) Buchenau, Abh. Naturwiss. Vereine Bremen 2: 2,4. 1868[1869]. Fig. 4a

Ervas $28-70 \mathrm{~cm}$ alt., glabras. Rizomas trígonos, 0,5-4,5 cm diâm. Folhas elípticas a obovadas, 10,518,5 cm compr., 5,7-12 cm larg.; ápice retuso a arredondado, levemente mucronulado; base aguda a levemente cordada; 9-14 nervadas. Pecíolo 15,5$34 \mathrm{~cm}$ compr., 0,4-0,6 mm diâm.; bainha 9-27 cm compr. Escapos maiores que os pecíolos, inflados, $13-50 \mathrm{~cm}$. Pedicelo floral $2-4 \mathrm{~cm}$ compr. Sépalas 1,3-1,5 cm compr., 1,2-1,3 cm larg. Pétalas não vistas. Estames ca. 30, estaminódios numerosos, ápice bidentado. Carpelos 16-18, ca. $8 \mathrm{~mm}$ compr. Aquênios 0,9-1,4 cm compr., 6-8 mm larg. Sementes numerosas, 1-1,4 mm compr.

Material examinado: Iguatu, 13.V.2010, L.R.O. Normando 83b (EAC). Lavras da Mangabeira, 25.IV.2001, fl. e fr., C.B.C. Oliveira s.n. (EAC). Tururu, 4.V.2006, fl., A.S.F. Castro 1774 (EAC).

A espécie ocorre desde o México ao sul da América do Sul (Haynes \& Holm-Nielsen 1992). No Brasil a espécie apresenta registros para as Regiões Norte, Nordeste, Sudeste e Sul (Sakuragui et al. 2010). As populações podem ser encontradas frequentemente na região semiárida do estado, com populações ocorrendo em alagados, na margem de estradas e lagoas temporárias, com solos ricos em matéria orgânica (Fig. 1-C5, H5, I6).

3.2 Limnocharis laforestii Griseb., Bonplandia 6(1): 11. 1858 . Fig. 4b

Ervas $23-28 \mathrm{~cm}$ alt., glabras. Rizomas esféricos, $1-2 \mathrm{~cm}$ diâm. Folhas elípticas a lanceoladas, $6-8 \mathrm{~cm}$ compr., 1,5-2,5 cm larg.; ápice mucronulado; base aguda a levemente cordada; $7-10$ nervadas. Pecíolo 12-17 cm compr., 2-3 mm diâm.; bainha 6-7 cm compr. Escapos menores que os pecíolos, não inflados, 10$12 \mathrm{~cm}$. Pedicelo floral 1,4-4 cm compr. Sépalas 1,3$1,5 \mathrm{~cm}$ compr., 0,6-0,9 cm larg. Pétalas não vistas. Estames 10-20, estaminódios ausentes ou menos que 10. Carpelos ca. 14, ca. $8 \mathrm{~mm}$ compr. Aquênios ca. 1,3 cm compr., $4 \mathrm{~mm}$ larg. Sementes numerosas, $0,7-0,9 \mathrm{~mm}$ compr.

Material examinado: Granja, 14.IV.2001, fl., A.S.F. Castro 956 (EAC). Iguatu, 13.V.2010, L.R.O. Normando 93 (EAC).

A espécie ocorre na América do Sul e Central (Haynes \& Holm-Nielsen 1992). No Brasil, a espécie apresenta registros nas Regiões Nordeste, Norte e Centro-Oeste (Sakuragui et al. 2010) e suas populações podem ser encontradas, frequentemente, na região semiárida do Ceará, em lagoas temporárias ou açudes. Existem registros de agrupamentos que podem ser encontrados em áreas alagadas da zona litorânea, estando relacionados a solos ricos em matéria orgânica (Fig. 1-B2 e H5). A espécie pode ser confundida com L. flava, sendo distinta pelo escapo sempre menor que o pecíolo e a frequente ausência de estaminódios (quando presentes, em número menor que 10).

4. Hydrocleys Rich., Mém. Nat. Hist. 1:368. 1815.

Ervas enraizadas no substrato com folhas flutuantes, monóicas. Folhas emergentes, elípticas a reniformes; acródomas; ápice agudo a arredondado, emarginado ou não; base cordada a arredondada; ductos secretores translúcidos ausentes; pecíolo cilíndrico, septados transversalmente ou não, glabros. Inflorescências cimosas flutuantes; pseudoviviparidade frequentemente presente; escapo flutuante, glabro, cilíndrico, não inflado, não alado; verticilo único. Brácteas elípticas a ovadas, membranáceas, glabras; ápice arredondado; base livre. Flores monóicas com pedicelo ereto; sépalas carenadas a cimbiformes, elípticas, coriáceas, lisas, glabras, persistentes, reflexas; pétalas pardas a amarelas, frequentemente com máculas amarelas a alaranjadas na base. Estames e estaminódios numerosos; anteras basifixas. Carpelos 4-7, pluriovulados. Aquênios ovados, abaulados, não apresentando sulco dorsal. Sementes numerosas.

\section{Chave para identificação das espécies de Hydrocleys ocorrentes no estado do Ceará}

1. Folhas elípticas a ovadas, pecíolos septados, sépalas carenadas, nervura central conspícua; flores amarelas com máculas centrais alaranjadas 4.1. H. martii

1'. Folhas orbiculares a reniformes, não septados, sépalas cimbiformes, nervura central inconspícua; flores pardas a alvas com máculas centrais amarelas 4.2. H. nymphoides

4.1 Hydrocleys martii Seub. Fl. bras. 3(1): 116. 1847.

Fig. 4 c-d

Ervas $12-50 \mathrm{~cm}$ alt., glabras. Rizomas esféricos, ca. 0,5-1 cm diâm. Folhas elípticas a orbiculares, 3-13,5 cm compr., 2,7-8,5 cm larg.; ápice agudo raramente emarginado; base cordada a arredondada; 7-10 nervadas. Pecíolos septados transversalmente, 3-36 cm compr., ca. 5 mm diâm.; 


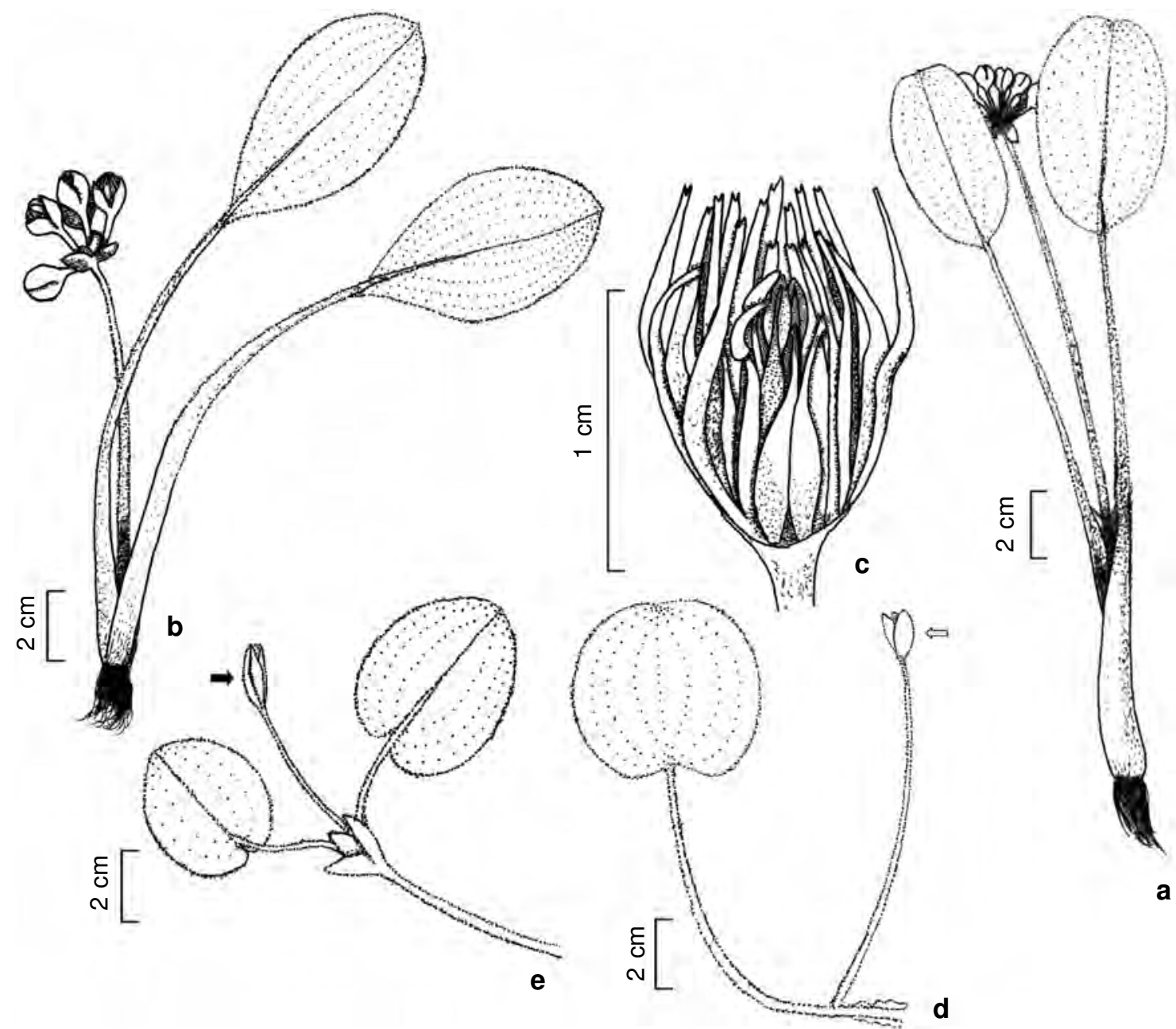

Figura 4 - a. Limnocharis flava (Normando 83b) - hábito. b. L. laforestii (Normando 93) - hábito. c-d. Hydrocleys martii (Normando 84) - c. secção longitudinal da flor mostrando os verticilos reprodutivos: os estaminódios laminares com ápices denteados, os estames e os carpelos em posição mais interna; d. detalhe da inflorescência, evidenciando a nervura central na sépala (seta). e. H. nymphoides (Normando 128) - detalhe da inflorescência, evidenciando a ausência da nervura central da sépala (seta).

Figure 4 - a. Limnocharis flava (Normando 83b) - habit. b. L. laforestii (Normando 93) - habit. c-d. Hydrocleys martii (Normando 84) - c. longitudinal section of flower showing the reproductive whorls: the laminar staminodia with dentate apices, the stamina and the inner position of the carpels; d. detail of the inflorescence, showing the main vein of the sepal (arrow); e. H. nymphoides (Normando 128) - e. detail of the inflorescence, showing the absence of main vein of the sepal (arrow).

bainha ca. $7 \mathrm{~cm}$ compr. Escapo 14-22 cm compr. Pedicelo floral 2-7 cm compr. Sépalas carenadas, elípticas, 1,3-2,3 cm compr., ca. 0,5 cm larg., nervura central conspícua. Pétalas amarelas, mácula alaranjada na porção inferior, $1,5-2,5 \mathrm{~cm}$ compr., ca. $3 \mathrm{~cm}$ larg. Estames ca. 15-17; estaminódios 3050. Carpelos 4-5, ca. $7 \mathrm{~mm}$ compr. Frutos e sementes não vistos.

Material examinado: Aiuaba, 19.V.2003, fl., L.Q. Matias 429 (EAC). Caridade, 20.III.2008, fl., A.B.T.
Holanda 07 (EAC). Crateús, 24.VI.2003, fl., L.Q. Matias 478 (EAC). Iguatu, 13.V.2010, L.R.O. Normando 84 (EAC). Jaguaribe, 20.IV.1997, fl., A.S.F. Castro s.n. (EAC 24838).

A espécie ocorre na América do Sul, do norte do Brasil ao Uruguai (Haynes \& Holm-Nielsen 1992, Sakuragui et al. 2010). As populações são comumente observadas nas margens de lagoas intermitentes ou perenes da região semiárida do Ceará (Fig. 1 -D5, F2, G6, H5, I3). 
4.2 Hydrocleys nymphoides (Willd.) Buchenau, Index Crit. Butom. Alism. Juncag. 9. 1868. Fig. 4e

Ervas ca. $28 \mathrm{~cm}$ alt., glabras. Rizoma não visto.

Folhas orbiculares a levemente reniformes, $5-7,9 \mathrm{~cm}$ compr., 5,2-9,1 cm larg.; ápice arredondado a emarginado; base cordada; 7 nervadas. Pecíolos não septados transversalmente, 6-21 cm compr., 6-8 $\mathrm{mm}$ diâm; bainha 2,5 cm compr. Escapo $10 \mathrm{~cm}$ compr. Pedicelo floral 6-16,5 cm compr. Sépalas cimbiformes, elípticas, 1,8-2 cm compr., 0,6-1 cm larg., nervura central inconspícua. Pétalas pardas raramente com máculas amarelas na base, ca. $2 \mathrm{~cm}$ compr, ca. 3,6 cm larg. Estames 20-26; estaminódios numerosos. Carpelos 6-7, 10-12 mm compr. Frutos e sementes não vistos.

Material examidado: Aiuaba, 30.V.1996, fl., M.I. Bezerra-Loiola et al. 191 (EAC). Iguatu, 14.V.2010, L.R.O. Normando 128 (EAC). Juazeiro do Norte, 17.V.2003, fl., L.Q. Matias 480 (EAC). São Gonçalo do Amarante, 10.XI.2007, M.F. Moro et al. 285 (EAC). Sobral, 23.VI.1994, A. Fernandes s.n. (EAC 21213).

A espécie ocorre desde o nordeste dos Estados Unidos até o sul do Brasil (Haynes \& Holm-Nielsen 1992). No Brasil, a espécie apresenta registros para as regiões Nordeste, Centro-Oeste, Suldeste e Sul (Sakuragui et al. 2010). No Ceará populações podem ser observadas nas margens de ambientes lênticos da região semiárida do estado e em alagados na zona litorânea (Fig. 1 -I3, H5, J5, C5 e C3). A espécie pode ser diferenciada facilmente de $H$. martii pela nervura central das sépalas pouco evidente (Fig. 4d-e) e pela corola com coloração mais clara.

\section{Agradecimentos}

Ao IC/CNPq, a bolsa do segundo autor. Ao biólogo Marcelo Telles (PPGERN/UFC) a preparação do modelo de mapa.

\section{Referências}

APGIII. 2009. An update of the Angiosperm Phylogenetic Group classification for the orders and families of flowering plants: APG III. Botanical Journal of the Linnean Society 161: 105-121.

Ceska, A. 1986. More on techniques for collecting aquatic and marsh plants. Annals of the Missouri Botanical Garden 73: 825-827.

Cook, D.K. 1996. Aquatic plant book. SPB, Amsterdam.

Cannon, W.A. 1949. A tentative classification of root systems. Ecology 30: 542-548.

COP-04. 1998. Fourth Ordinary Meeting of the Conference of the Parties to the Convention on Biological Diversity. Bratislava, Slovakia. Disponível em <http://www.cbd.int/convention/cops.shtml>. Acesso em 4 Jan 2010.
Cronquist, A. 1981. An integrated system of classification of flowering plants. Columbia University Press, New York. 1262p.

Cronquist, A. 1988. The evolution and classification of flowering plants. New York Botanical Garden, New York. 555p.

Dahlgren, R.M.T. \& Rasmussen, F.N. 1983. Monocotyledon evolution: characters and phylogenetic estimation. Evolution Biology 16: 255-395.

Dahlgren, R.M.T.; Clifford, H.T. \& Yeo, P.F. 1985. The families of the monocotyledons. Springer-Verlag, Berlin. 501p.

Haynes, R.R. 1984. Techniques for collecting aquatic and marsh plants. Annals of Missouri Botanical Garden 71: 229-231.

Haynes, R.R. \& Holm-Nielsen, L.B. 1992. The Limnocharitaceae. Flora Neotropica 56: 1-32.

Haynes, R.R. \& Holm-Nielsen, L.B. 1994. The Alismataceae. Flora Neotropica 64: 1-112.

Haynes, R.R.; Les, D.H. \& Holm-Nielsen, L.B. 1998. Alismataceae. In: Kubitzki, K. (ed.). The families and genera of vascular plants - Flowering plants monocotyledons Alismatanae and Commelinanae (except Graminae). Vol. 4. Springer-Verlag, Berlin. Pp. 11-15.

IPNI. 2010. The International Plant Names Index. Disponível em <http://www.ipni.org >. Acesso em 7 Set 2010.

Irgang, E.B. \& Gastal, C.S. 1996. Macrófitas aquáticas da planície costeira do RS. Ed. Autores, Porto Alegre. 290p.

Harris, J.G. \& Harris, M.W. 1997. Plant identification terminology. An illustrated glossary. Spring Lake Publishing, Payson. 188p.

Les, D.H. \& Haynes, R.R. 1995. Systematics of subclass Alismatidae: a synthesis af approaches. In: Rudall, P.J.; Cribb, P.J.; Cutler, D.F. \& Humphries, C.J. (eds.). Monocotyledons: systematic and evolution. Royal Botanic Gardens, Kew. Pp. 353-377.

Lehtonen, S. 2008. An interative approach to species delimitation in Echinodorus (Alismataceae) and the description of two new species. Kew Bulletin 63: 525-563.

Li, X. \& Zhou, Z. 2009. Phylogenetic studies on the core Alismatales inferred from morphology and $r b c \mathrm{~L}$ sequences. Progress in Natural Science 19: 931-945.

Matias, L.Q. 2007. O gênero Echinodorus (Alismataceae) no domínio da caatinga brasileira. Rodriguésia 58: 743-774.

Matias, L.Q. 2010. Alismataceae. In: Lista de espécies da flora do Brasil. Jardim Botânico do Rio de Janeiro. Disponível em <http://floradobrasil.jbrj.gov.br/2010/ FB004994>. Acesso em 16 Dez 2010.

Matias, L.Q. \& Irgang, B.E. 2006. Taxonomy and distribution of Sagittaria (Alismataceae) in Northeastern Brazil. Aquatic Botany 84: 183-190.

Matias, L.Q. \& Soares, G. 2009. Morphology and micromorphology of the seed coats of species of 
Echinodorus (Alismataceae) from Brazilian Northeastern. Boletim do Museu Emilio Goeldi, Ciências Naturais 4: 165-173.

Pichon, M. 1946. Sur lês alismatacées et les butomacées. Notulae systematicae. Herbier Du Museum de Paris, Paris. Pp. 170-183.

Sakuragui, C.M.; Matias, L.Q. \& Lopes, R.C. 2010. Limnocharitaceae. In: Lista de espécies da flora do Brasil. Jardim Botânico do Rio de Janeiro. Disponível em <http://floradobrasil.jbrj.gov.br/2010/ FB102846>. Acesso 17 Dez 2010.

Stevens, P.F. 2001 [onwards]. Angiosperm Phylogeny Website. Version 9, June 2008 [and more or less continuously updated since]. Disponível em <http://www.mobot.org/ MOBOT/research/APweb/>. Acesso em 4 Abr 2011.
Takhtajan, A. 1980. Outline of the classification of flowering plants (Magnoliophyta). The Botanical Review 46: 225-259.

Thiers, B. 2010 [continuously updated]. Index Herbariorum: A global directory of public herbaria and associated staff. New York Botanical Garden's Virtual Herbarium. Disponível em: <http:// sweetgum.nybg.org/ih/>. Acesso em 10 Nov 2010.

Thorne, R.F. 1992. Classification and geography of the flowering plants. The botanical review 58: 225-348.

Thorne, R.F. 2000. The classification and geography of the monocotyledon subclasses Alismatidae, Liliidae, and Commelinidae. In: Nordenstam, B.; El-Ghazaly, G.; Kassas, M. \& Laurent, T.C. (eds.). Plant systematic for the $21^{\text {st }}$ century. Portland Press, London. Pp. 75-124.

\section{Lista de exsicatas}

Andrade Lima, D. 5099 (2.7). Andrade Neto, M. s.n. (EAC 43681) (2.3), s.n (EAC 43682) (2.5), s.n (EAC 43683) (2.4). Andrade, I.M. s.n. (EAC 35208) (2.2). Barros, E.O. 194 (2.2), 280 (2.6), s.n. (EAC 35207) (2.2). Bezerra-Loiola, M.I. 191 (4.2), s.n (EAC 35209) (2.2). Castro, A.S.F. 1824 (2.2), 1772 (2.6), 1771 (1.2), 1774 (3.2). Coelho, L. C. s.n. (EAC 18738) (2.6), (EAC 18735) (2.6). Duarte, A.P. 1408 (2.2). Duarte, C. 1238 (2.6). Eugenio, J. 227 (2.5). Fernandes, A. s.n (EAC 22996) (1.2), s.n (EAC 8372) (2.5), s.n (EAC 12996) (2.6), s.n (EAC 32888) (2.6), s.n (EAC 13218) (2.6), s.n (EAC 1635) (2.6). Figueiredo, M.A. 201 (2.2), 606 (2.2). Gardner, G. 1860 (2.1). Holanda, A.B.T. 03 (4.1), 04 (4.1), 07 (4.1). Lemos, J.R. 253 (2.2). Lima-Verdes, L.W. 280 (2.6), 282 (2.2), 804 (2.2). Löfgren, A. 390 (2.1). Luetzelburg, P. 25911 (2.1), 28030 (2.6). Macêdo, D. s.n. (EAC 23372) (2.6). Matias, L.Q. 50 (2.7), 69 (2.6), 198 (2.6), 217 (2.6), 338 (2.4), 343 (2.6), 344 (2.6), 345 (2.6), 346 (2.5), 347 (2.6), 348 (2.4), 349 (2.2), 350 (2.6), 352 (2.2), 353 (2.4), 354 (2.5), 355 (2.6), 357 (2.6), 358 (2.6), 360 (2.6), 361 (2.3), $363(2.6), 364(2.6), 367(2.6), 373(2.5), 375(2.2)$, 378 (2.4), 400 (2.6), $418(2.4), 420$ (2.4), 421 (2.2), 422 (2.6), 425 (2.6), 428 (2.6), $432(2.6), 433(2.6), 434(2.5), 442(2.4), 443(2.5)$, 444 (2.6), 446 (2.4), 447 (2.4), 455 (1,1), 461 (2.5), 462 (2.2), 463 (2.6), 464 (2.6), 465 (2.2), 466 (2.6), 467 (2.6), $469(2.6), 480(4,2)$, 481 (2.6), 482 (2.3), 483 (2.2), 489 (2.6), 490 (2.6), 519 (2.6), 529 (2.6), 530 (2.7). Moro, M.F. 285 (4,2). Normando, L.R.O. 84 (4.1), 109 (4.1), 502 (4.1), 339 (4.1), 398 (4.1), 443 (4.1), 459 (4.1), 182 (4.2), 112 (2.5), 474 (2.5), 86 (2.6), 92 (2.6), $246(2.6), 229$ (2.6), 257 (2.6), 349 (2.6), 401 (2.6), 408 (2.6), 424 (2.6), 448 (2.6), 467 (2.6), 475 (2.6), 506 (2.6), 5 (2.3), 512 (2.3), 93 (3.1), 500 (3.1), 83b (3.2). Oliveira, E.A.R. 11 (2.6). Sousa, D.J.L. 02 (2.6), 07 (2.6), 35 (2.6), $36(2.6), 50$ (2.6). Souza, E.B. 496 (2.6), s.n. (EAC 18363) (2.6). Trigueiro, E. s.n. (EAC 38083) (2.6). Viana, F.A. s.n (EAC 11906) (2.6). 